\title{
Comparison between Thyristor Switched Series Capacitors and Thyristor Switched Parallel Capacitors for wind power systems - A simulation study
}

\author{
D. KALPAKTSOGLOU, \\ Department of Mechanical Engineering \\ International Hellenic University, \\ Terma Magnesias, 62125, Serres, \\ GREECE \\ A. TSIAKALOS, \\ Dept. of Applied Informatics, \\ University of Macedonia, \\ 54006, Thessaloniki, \\ GREECE \\ S. Pouros, \\ Department of Information and Electronic Engineering, \\ International Hellenic University, \\ PB141, Sindos, Thessaloniki, \\ GREECE \\ M. ROUMELIOTIS, \\ Dept. of Applied Informatics, \\ University of Macedonia, \\ 54006, Thessaloniki, \\ GREECE
}

Abstract: - This paper compares by simulation the Thyristor Switched Series Capacitors (TSSC) Circuit with the Thyristor Switched Parallel Capacitors (TSPC) Circuit for wind turbines. The well-known TSSC circuit belongs to the Controlled Series Capacitor (CSC) circuits that have been used in power transmission lines in order to correct the power factor and improve the performance of the electrical system. Such a circuit can be used in wind power systems to improve and maximize the efficiency of a wind turbine. A typical direct-drive wind power system employs variable speed electric generators, but the downside is that systems like that suffer from high inductive reactance. A TSSC circuit, therefore, is able to counteract for any reactive losses, and improve the power factor as well as the efficiency. The main issue with the TSSC circuit is the use of a high number of capacitors that must be connected in series, which can increase the cost and the maintenance of the controller. This paper introduces a novel circuit with different control technique than the TSSC that employs capacitors in parallel configuration. The novel TSPC circuit was simulated in PSPICE and the benefits as well as the drawbacks are described.

Keywords: reactive power control, phase control, thyristor circuits, switching converters, energy efficiency

Received: July 16, 2020. Revised: November 11, 2020. Accepted: November 22, 2020. Published: November 30, 2020. 


\section{Introduction}

CURRENTLY, our civilisation's economy is based upon conventional and non-renewable energy sources such as petroleum, coal, natural gas and nuclear substances, which have been proven to be extremely destructive and very harmful to the environment and to human health. Therefore, the Kyoto Protocol for greenhouse gas reduction was entered into force in 2005 .

In order to reduce greenhouse gases and to reach the target of the anthropogenic emissions of $\mathrm{CO} 2$ that was set by the Kyoto Protocol, conventional fuels should be replaced by Renewable Energy Sources. In the last two decades, significant effort has been put to wind power, whose annual growth is over $20 \%$ and this resulted to a capacity of 318,105 MW, recorded at the end of 2013. Today, wind power farms have been installed and used on a commercial basis, in more than 83 countries [2].

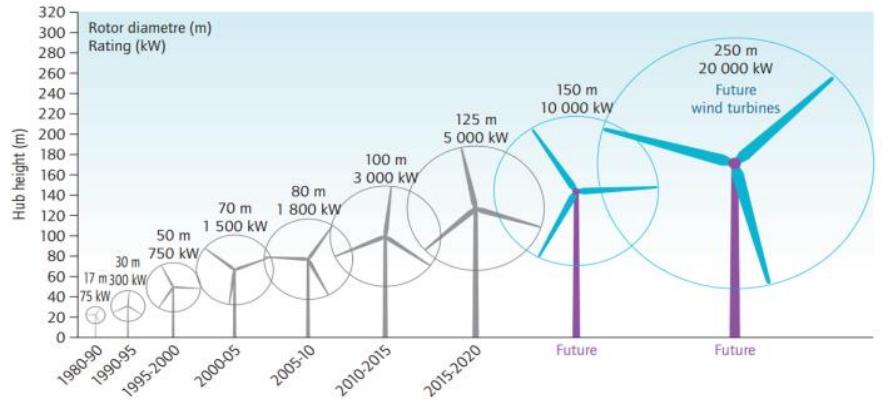

Fig. 1. Evolution of wind's turbine rotor diameter and power from 1980 [2].

Wind turbines, currently, reached a 5,6MW-7MW of rated electrical output power, with rotor's swept area of more than $20,000 \mathrm{~m}^{2}$. Figure 1 shows the progression in the diameter and the rated electrical output power of wind turbines as it has been recorded in the last 30 years. Although all those wind turbines have been optimised using better and lighter materials as well as more aerodynamic blades, in theory the maximum aerodynamic conversion efficiency from wind to mechanical power is only $59 \%$.

In practice, the average year-round efficiency of most turbines is about half for several reasons. Firstly, it is essential for a wind turbine to automatically shut down and stop its operation when very high winds are present. Further, generator and gearbox losses have also an effect on average efficiency, and finally, it is reasonable that the machine operates not at its optimum working point; therefore, there are some efficiency losses [3].

\section{Wind Turbines}

The majority of wind turbines can be found either with their axis in horizontal (HAWTs) or in vertical position (VAWTs) [3].

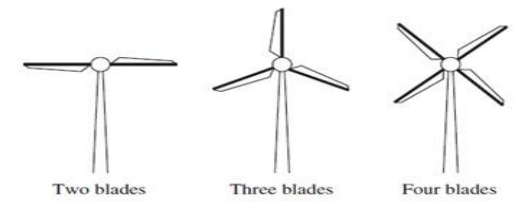

Fig. 2. Main types of Horizontal axis wind turbines [3]

The basic HAWT system, for electric production, consists of a large rotor comprising two, three or four blades, as shown in Figure 2. The majority of the turbines use three blades in order to have smoother rotational operation, lower noise and lower manufacturing cost.

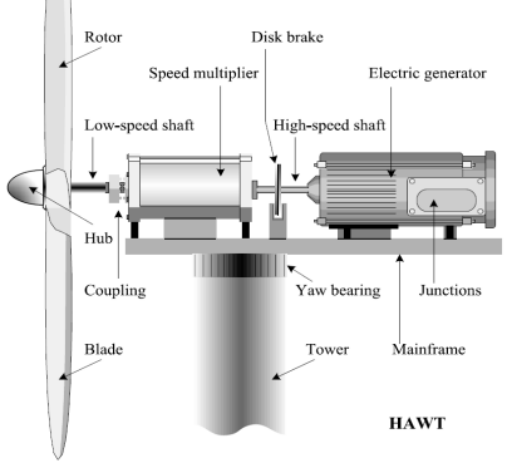

Fig. 3. Schematic diagram of equipment contained in a nacelle of a HAWT [4]

Figure 3 shows the nacelle of a wind turbine which is a weather tight compartment including all the main parts for converting the mechanical energy to electricity and it is located at the top of a tower of an HAWT. In order to increase the slow rotation of the HAWT's shaft a gearbox is used and the energy is passed to the generator. Both gearbox and generator are directly attached to the turbine's shaft though a braking system as shown above. The electrical power generated is fed to the grid [3].

The rotational speed of a rotor shaft is between 5 and 20 rpm while electric generators operate between 800 and $3000 \mathrm{rpm}$. Therefore, a speed-up gearbox is essential in order to level up the speed [3]. However, the downfall of using gearboxes is the need for frequent maintenance and in order to overcome this problem direct-drive systems have been developed, where the rotor is connected directly to the generator.

\subsection{Types of Wind Turbine's Gearboxes}

There are several types of gearboxes that can be used in wind turbines, with the most common being the conventional, the magnetic, the CVT, and the torque splitting.

Torque Splitting - For solving some of the above-mentioned gearbox problems, on 2.5 MW plus size wind turbines, this technique uses a multiple-path gearbox design to split the torque from the rotor blades evenly between four generators that are operated in parallel [4]. 
Continuously Variable Transmissions, CVTs Transmissions of the CVT type can vary continuously through an infinite number of gearing ratios, in contrast to the standard gearbox, which varies between a set number of specific gear ratios [4].

Magnetic bearings-are considered quite promising solution in order to solve the shaft misalignment problem. The benefits of magnetic bearings include durability, smaller frictional losses, and increased reliability at a reduced weight.

The maintenance of all the above types of gearboxes as well as the conventional gearbox of a wind turbine is very expensive. In order to extend the life-span of a gearbox, regular maintenance is needed, which adds to the overall cost. Therefore, the gearbox reduces the efficiency of a wind turbine due to inertia; it is vulnerable to wind gusts and the most likely part of a wind turbine to fail.

One way to improve the efficiency of a wind turbine and make it more fault-tolerant is to avoid using gearboxes and use direct-drive systems instead. At gearless or direct-drive wind turbines, the rotor is the only moving part that transfers the energy from the blades to the electric generator via a low-speed shaft. Those wind turbines eliminate gearboxes by replacing them with variable speed electric generators and solid-state electronic converters.

Overall, it can be said that the advantages of the direct-drive mechanism for wind turbines, are the increased efficiency, as the power is not wasted in friction, the reduced noise, as it is a simpler device and finally, the high torque at low rpm.

Direct-drive wind turbines operate within a certain rpm range, and the output voltage and frequency from direct-coupled generator vary slightly over time. Therefore, these systems rectify the output three-phase voltage from the generator to DC. A DC link and inverter convert the DC voltage to become suitable for transmitting it to the electrical grid.

\section{Operation with An Uncontrolled Single-Phase Diode Bridge Rectifier}

The specifications of the national grid require a fixed voltage and fixed frequency. However, due to wind's speed variations, the output voltage and the frequency of the wind's turbine electric generator varies too. Therefore, the variable AC signal from the wind turbine electric generator has to be converted to DC signal, with the use of a rectifier. The rectified DC signal can then be converted back to $\mathrm{AC}$ at a fixed amplitude and frequency. An arrangement that would allow this to take place is shown in Figure 4.

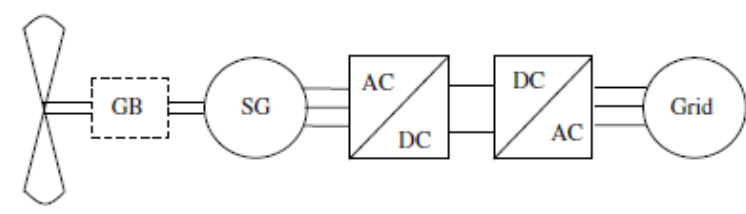

Fig. 4. Wind turbine with synchronous generator [5].

In Figure 4 the wind turbine's rotor is shown on the left-hand side and it is coupled to an electric generator (SG) via a gearbox. The electric generator's output is connected to a rectifier (AC/DC), in order to converter the AC voltage to DC. At the output of the rectifier a DC filter is used and then it is directly connected to an inverter (DC/AC). A transformer is connected at the output of the inverter to increase the $\mathrm{AC}$ voltage and to connect the wind turbine to the grid [6-9]. The inverter may be either a SCR controlled inverter or a PWM inverter, depending on the situation [5].

In wind turbine systems one of the most important factors of their design is their cost and therefore, the usage of a simple and low-cost AC to DC rectifier is preferred. This AC/DC single-phase diode bridge rectifier is considered the simplest possible rectifier circuit that can be used in such applications. The conversion from AC/DC usually employs a voltage feedback control. However, this kind of standard single-phase diode bridge rectifier does not include any feedback control loop. Therefore, the output voltage is determined completely by the amplitude of the input voltage. A schematic diagram of the AC/DC standard single-phase diode bridge rectifier circuit is shown in Figure 5.
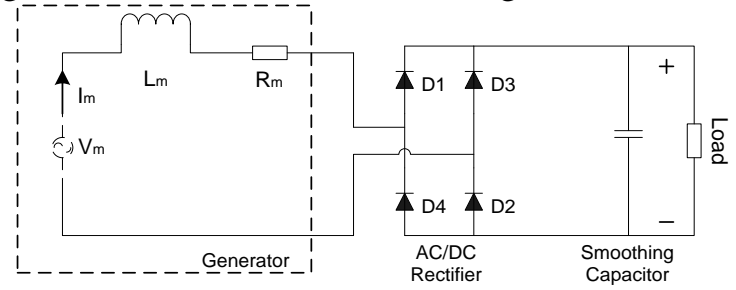

Fig. 5. Standard single-phase rectifier circuit

This type of rectifier provides a DC voltage at the output, for any AC voltage input. During the positive half cycle of the back-EMF voltage waveform, diodes D1 and D2 are forward biased so they conduct. During the negative half cycle diodes D1 and D2 are reverse biased and only D3 and D4 conduct. Figure 6 below shows the simulation results for the standard single-phase rectifier circuit (Fig. 5).

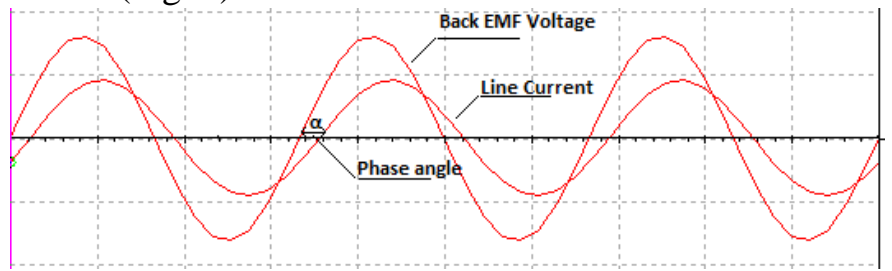

Fig. 6. Generator back EMF and the fundamental current waveform showing the effects of generator inductance [10]. 
However, the presence of high generator inductance does not allow current to be directly transferred from diodes D1 \& D2 to D3 \& D4. Therefore, a period of overlap is present when current in D1 and D2 falls, while current in D3 and D4 rises, which causes a phase shift between the back EMF voltage and the first harmonic of the generator AC current, as shown in Figure 6.

This phase shift results in losses of available power that could be transferred from the electric generator to the grid.

Assuming a purely sinusoidal back emf voltage, the generator power output $\mathrm{P}$ is given by the following Equation:

$$
P=V_{m} I_{m 1} \cos \alpha
$$

where $\alpha$ is the phase angle between $V_{m}$ and $I_{m 1}$ and it can take values between 0 and 1 . When $\cos \alpha$ is 0 then all the available power $\mathrm{P}$ becomes reactive and the real power is equal to 0 . Minimising the angle $\alpha, \cos \alpha$ will increase and thus the real power delivered to the load will clearly increase. This can be achieved if a Series Resonant Circuit (series RLC) is used. In a series-resonant RLC circuit the inductive reactance of the inductor becomes equal in value to the capacitive reactance of the capacitor. In other words, $X_{L}=X_{C}$. The point at which this occurs is called the Resonant Frequency point, $(f r)$ of the circuit, and the maximum power is delivered when the system works at this resonant frequency point [10].

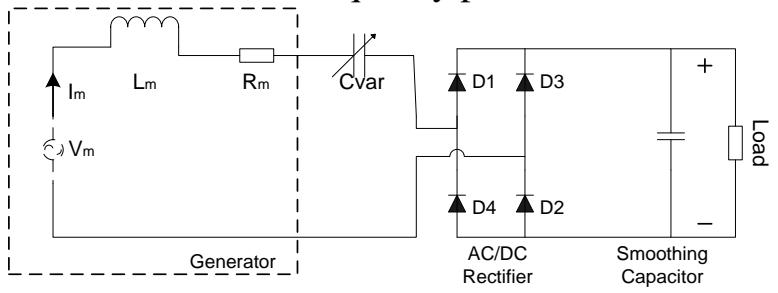

Fig. 7. Generator with variable capacitor [10]

In order to achieve this, a variable capacitor for high voltage and high current is needed, but such a variable capacitor is not commercially available and therefore Controlled Series Capacitor (CSC) rectifiers could be used.

\subsection{Thyristor Switched Series Capacitor Rectifier (TSSC)}

The TSSC circuit (Figure 8) consists of a number of capacitors in series, each shunted by a switch composed of two anti-parallel thyristors [11]. All capacitors have the same value $\mathrm{C}_{\text {TSSC }}$.

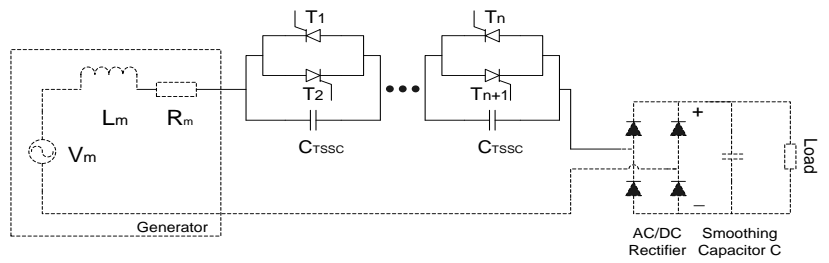

Fig. 8. TSSC main circuit [12]

The overall capacitance is controlled by conducting or blocking each of the thyristor pairs. If a thyristor pair conducts, the capacitor $\mathrm{C}_{\mathrm{TSSC}}$ is short circuited. If a thyristor pair is open, the value $\mathrm{C}_{\text {TSSC }}$ is added to the total capacitance $\mathrm{C}_{\mathrm{T}}$. The total capacitance of the circuit is given by Equation 2:

$$
C_{T}=\frac{C_{T S S C}}{m}
$$

where $\mathrm{m}$ is the number of active capacitors. If all capacitors are bypassed the equivalent capacitance becomes $\mathrm{C}_{\mathrm{T}}=0 \mathrm{~F}$ [13-15]. In order to correct the power factor and therefore increase the output power, the capacitance of the system $X_{C}$ should be equal to inductance $\mathrm{X}_{\mathrm{L}}$ as shown in Equation:

$$
X_{c}=X_{L} \Rightarrow \frac{1}{\omega C_{T}}=\omega L \Rightarrow C_{T}=\frac{1}{\omega^{2} L}
$$

Since all thyristors are "naturally" commutated, they turn off when the current crosses zero. It is only at that moment that a capacitor can be inserted into the line, as shown in Figure 9.

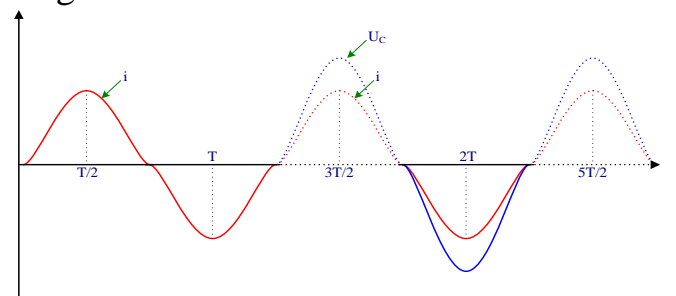

Fig. 9. Capacitor insertion at zero current voltage [12]

Once the capacitor is in line, during the full half-cycle of the line current it will be charged to its maximum, and during the negative line current cycle it will be discharged to zero $[16,17]$.

For our simulation model, a PMSG with 4 poles has been used, although PMSGs with more poles have been reported $[18,19]$. The frequency at the generators with high number of pole pairs is much closer to the desired $50 \mathrm{~Hz}$ electric grid frequency, compared to PMSG with low number of pole pairs, but the inductive reactance is increased, as it is proportional to the frequency, as shown below:

$$
X_{L}=L \omega=L 2 \pi f
$$

The circuit shown in Figure. 8 was simulated for electrical frequencies between $0.4 \mathrm{~Hz}$ and $1.333 \mathrm{~Hz}$. To correct the power factor when the blades rotation speed is 
20 rpm, a maximum of 1627 capacitor blocks, each having a capacitance of $358 \mathrm{mF}$, have been used. This value is for simulation purposes only, as in practice such a high value of capacitors is not feasible. To simplify the simulation a maximum number of 1627 capacitors was used.

Table I shows the number of active capacitors for various speeds of PMSG.

TABLE I

NUMBER OF ACTIVE CAPACITOR BLOCKS

\begin{tabular}{cc}
$\boldsymbol{\omega}(\mathbf{r p m})$ & $\mathbf{m}$ \\
\hline 6 & 1 \\
8 & 21 \\
10 & 35 \\
12 & 188 \\
14 & 369 \\
16 & 651 \\
18 & 1053 \\
20 & 1627
\end{tabular}
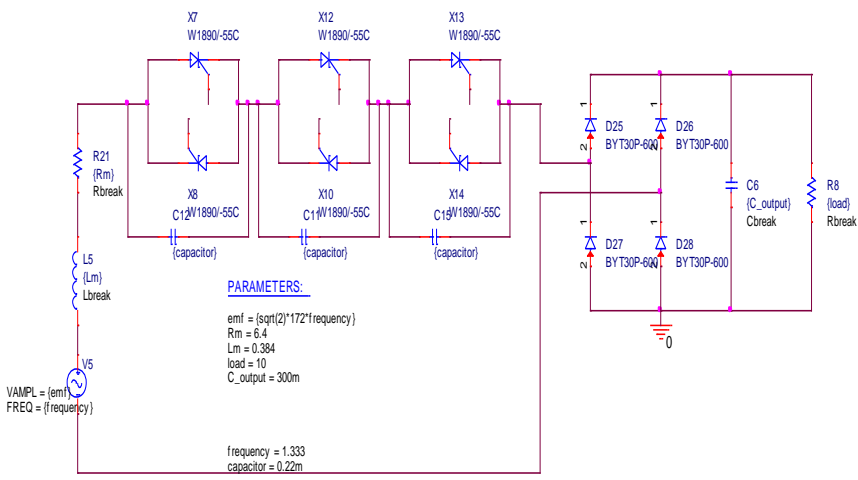

Fig. 10. TSSC PSPICE model

The TSSC circuit was simulated in PSPICE. The thyristor model that was used is the "W1890/-55C" which has an internal resistance of $1 \mathrm{Ohm}$. For the diodes in the bridge rectifier, the model "BYT30P-600" was used (Figure 10).

Simulation has been carried out and the results for the phase current, the output voltage and the output power are shown at the Table II.

TABLE II.

THE SIMUATION RESULTS

\begin{tabular}{cccccc}
\hline $\begin{array}{c}\boldsymbol{\omega} \\
(\mathbf{r p m})\end{array}$ & $\begin{array}{c}\text { Electric } \\
\text { Freq. } \\
(\mathbf{H z})\end{array}$ & $\begin{array}{c}\text { Back } \\
\mathbf{e m f} \\
(\mathbf{V})\end{array}$ & $\begin{array}{c}\text { Gen's } \\
\text { current } \\
(\mathbf{A})\end{array}$ & $\begin{array}{c}\text { DC } \\
\text { voltage } \\
(\mathbf{V})\end{array}$ & $\begin{array}{c}\text { Output } \\
\text { Power } \\
(\mathbf{W})\end{array}$ \\
\hline 6 & 0,400 & 68,8 & 5,1 & 40,1 & 161,6 \\
8 & 0,533 & 91,7 & 6,71 & 53,8 & 291,2 \\
10 & 0,667 & 114,7 & 8,53 & 67,7 & 461,7 \\
12 & 0,800 & 137,6 & 9,59 & 74,2 & 554 \\
14 & 0,933 & 160,5 & 11,12 & 88,2 & 781,7 \\
16 & 1,067 & 183,5 & 13 & 101,6 & 1036,2 \\
18 & 1,200 & 206,4 & 14,22 & 114,4 & 1314,5 \\
20 & 1,333 & 229,3 & 15,62 & 127 & 1617,2
\end{tabular}

As it is shown above, the output power is very close to the ideal case. When the inductive reactance is equal to capacitive reactance, the system is at its resonant point and operates with maximum efficiency without any reactive losses. The downside is the use of numerous blocks $\mathrm{m}$ (anti-parallel thyristor shunted to a capacitor), especially as the frequency increases. In this case for $1.333 \mathrm{~Hz}$ frequency 1627 blocks have been used, making this circuit non-attractive for further research at wind turbines.

\subsection{Thyristor Switched Parallel Capacitor Rectifier (TSPC)}

One way to overcome the huge number of blocks is to stack the capacitors in parallel. In this topology, its block consists of 2 anti-parallel thyristors connected in series to a capacitor, where each capacitor has a different value, and the total capacitance is $\mathrm{C}_{\mathrm{T}}$.

Figure 11 below shows the PSpice model for the TSPC circuit.

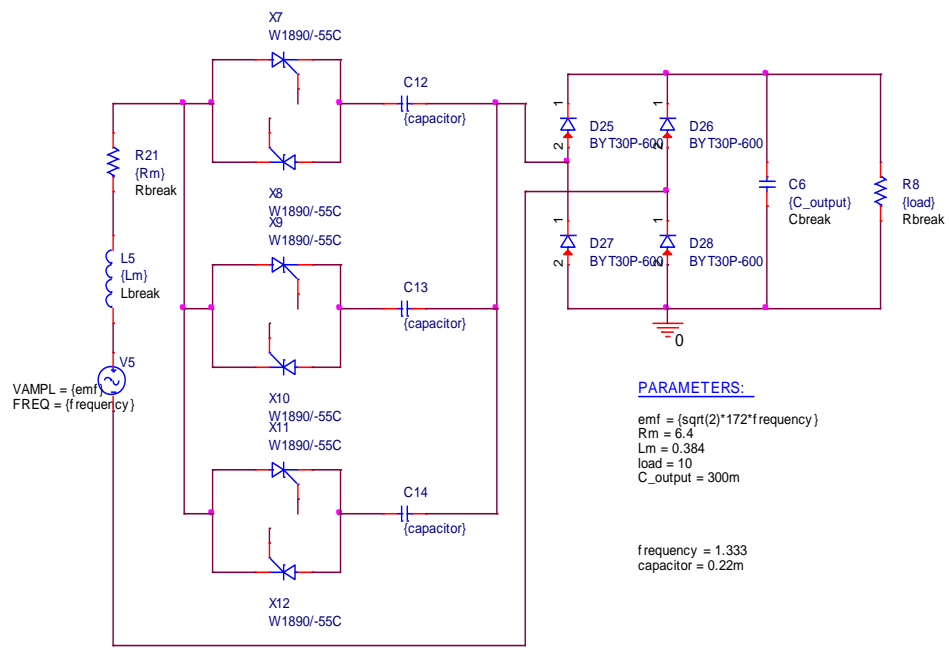

Fig. 11. TSPC PSPICE model

It must be added that the switching devices can be controlled using an FPGA. The use of a computational system to control the switching devices is inevitable and the simplicity of the algorithm is beneficial for the reliability of the system. The low-level programming that uses a hardware descriptive language, it benefits from parallel processing and output of the data. Initial implementations are already providing positive feedback. A Cyclone V FPGA is more than capable to host the algorithm to control the switching device.

As it was mentioned before, each block uses different values of capacitors. These values are shown in the Table III below.

TABLE III.

CAPACITOR VALUES

\begin{tabular}{ccc}
\hline \hline $\boldsymbol{\omega}(\mathbf{r p m})$ & $\begin{array}{c}\text { Single Capacitor } \\
\text { value }(\mathbf{m F})\end{array}$ & $\mathbf{m}$ \\
\hline 6 & 358 & 1 \\
8 & 17,1 & 1 \\
10 & 10,2 & 1 \\
12 & 1,9 & 1 \\
14 & 0,97 & 1
\end{tabular}




$\begin{array}{lll}16 & 0,55 & 1 \\ 18 & 0,34 & 1 \\ 20 & 0,22 & 1\end{array}$

This topology requires only 1 active block, and therefore, the $\mathrm{m}$ value for all the frequencies is equal to 1 . It is clearly shown that it is feasible to drastically reduce the number of blocks used in TSSC. In addition, the resistive losses of the thyristors will be reduced. The simulation results using the TSPC circuit are shown in Figure 12 and Figure 13.

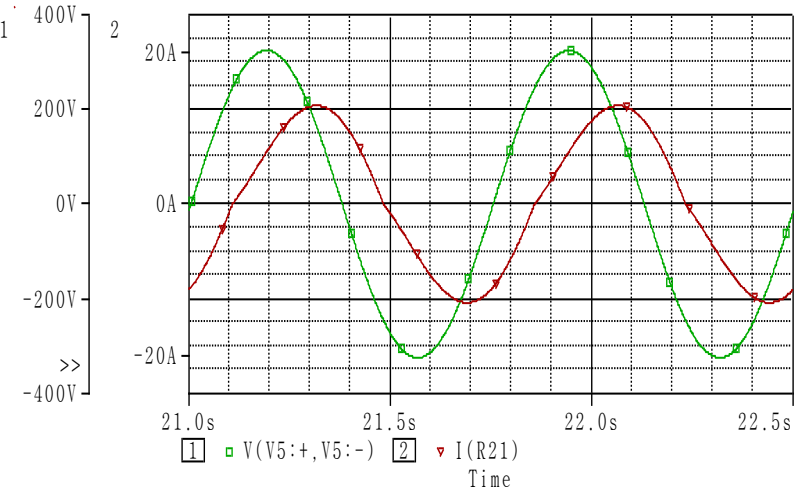

Fig. 12. The voltage and current waveforms before the insertion of the TSPC circuit.

Figure 12 shows the phase delay between the current and the voltage. This system has low power factor and it suffers from reactive losses. Figure 13 shows the voltage and the current lines after the insertion of the proposed TSPC circuit. The power factor is nearly 1 and the efficiency is greatly improved. The simulation results for the phase current, output voltage and the output power of the TSPC circuit are presented in Figure 14, 15 and 16.

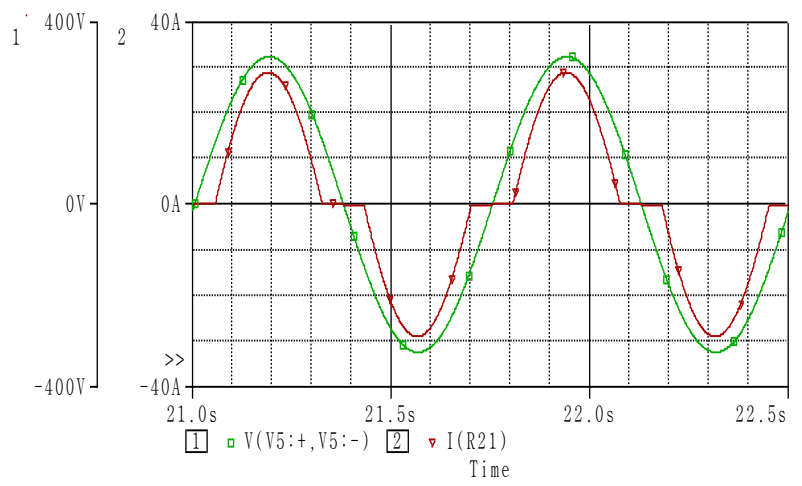

Fig. 13. The voltage and current waveforms after the insertion of the TSPC circuit.

All the simulation results regarding the phase current, the output voltage, and the output power using a $1.5 \mathrm{kVA}$ PMSG model in PSpice are shown in Figure 14 and Figure 15 below.

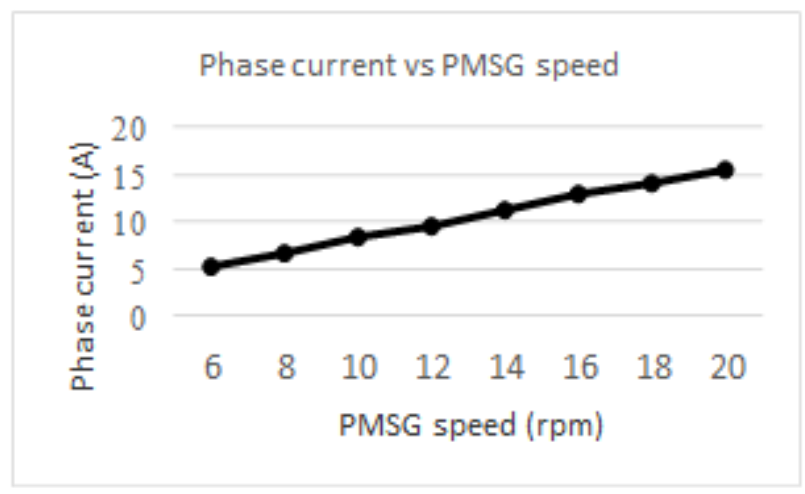

Fig. 14. Phase current vs PMSG speed

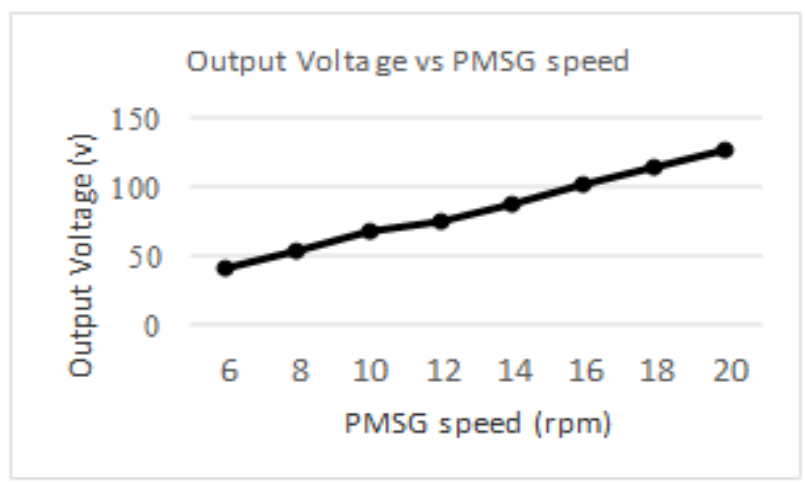

Fig. 15. Output Voltage vs PMSG speed

Figure 14 and Figure 15 show the phase current and the output voltage in relation to the generator's speed respectively. Figure 16 shows the output power in relation to the generator's speed.

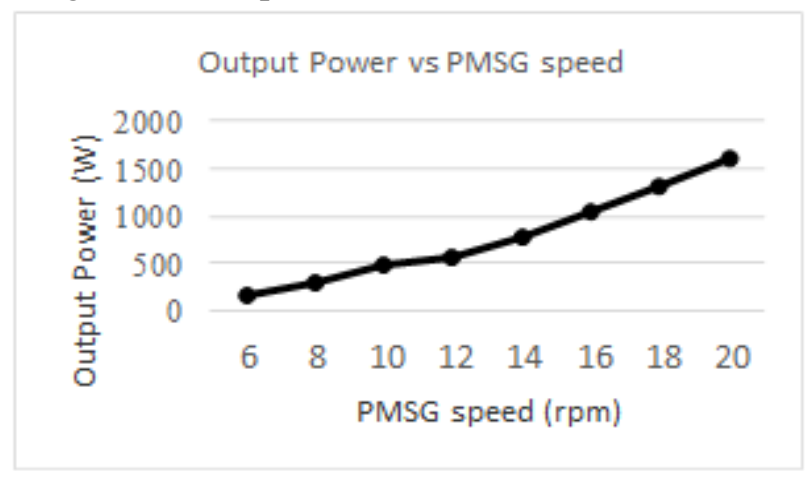

Fig 16. Output Power vs PMSG speed

It can be clearly seen that the output power is very close to the ideal case, and similar to the TSSC circuit results. The only difference is that lower values of capacitors have been used. In addition, the resistive load is much lower, due to fact that only 1 block, meaning only 1 pair of anti-parallel thyristors are active.

\section{Conclusion}

The paper describes the operation of a Thyristor Switched Series Capacitors (TSSC) circuit for wind turbines. A typical wind turbine uses a gearbox and in order to 
overcome the numerous problems of the usage of gearboxes and to improve the efficiency of a wind turbine, the usage of direct-drive systems was considered as the most appropriate method. The downside is that the electric frequency is not fixed and is much lower than $50 \mathrm{~Hz}$ or $60 \mathrm{~Hz}$ that the electric grid requires. Therefore, by using diode bridge rectifier, it is possible to convert the low variable AC signal to DC and then with an Inverter back to grid-required AC signal. However, this topology has low power factor due to high inductive reactance of the generator. Today, the majority of the Wind Turbines employs a PWM rectifier to convert the variable ac signal to DC rather than a diode bridge rectifier, but such rectifiers have very high switching losses due to the high switching frequency [20].

In this paper, controlled series compensation is proposed to compensate the inductive reactance of the generator. The technique is used in $\mathrm{AC}$ power transmission networks to ease line congestion and change network voltage profiles but has never been suggested for a variable-frequency, variable-voltage application such as in wind turbines.

A TSSC circuit, capable of correcting the converter's operating power factor, over the whole of the operating frequency range and thus maximising the wind's turbine energy conversion, has been studied, simulated and presented in this paper.

Although the switching frequency of the Thyristors are kept low and specifically equal to the line frequency, keeping the switching losses to minimum compared to PWM rectifiers, this TSSC circuit uses a high number of capacitors making it practically not feasible to be implemented for such projects. A way to overcome this problem is the use of Thyristor switched Parallel Capacitor TSPC. This new topology utilizes only one capacitor for every change in the system's frequency. This circuit has been simulated using a standard diode bridge circuit and a $1.5 \mathrm{kVA}$ PMSG model. The performance characteristics are the same with the TSSC but this time the number of capacitors is drastically lower. The power factor achieved in simulations with the proposed TSPC circuit was near unity over the entire operating range, maximising the energy transfer from the machine to the load.

\section{APPENDIX}

PMSG parameters:

Maximum output volt-amperes: $1.5 \mathrm{kVA}$

Maximum back EMF \& Current: $230 \mathrm{~V}$

Maximum Current: 16A

Winding resistance: $6.4 \Omega$
Winding inductance: $384 \mathrm{mH}$

\section{References:}

[1] M. P. Dave and N. Kumar, "Auxiliary controlled SVS and controlled series compensation for flexible AC transmission systems," Proceedings of International Conference on Power Electronics, Drives and Energy Systems for Industrial Growth, vol.1. pp. 121-127, 1996.

[2] Marcelo De Lellis Costa de Oliveira, Airborne Wind Energy with Tethered Wings: Modeling, Analysis And Control, Ph.D. dissertation, Federal University of Santa Catarina, Florianopolis, 2016.

[3] S. Kalogirou, Solar energy engineering: processes and systems. Amsterdam; London: Elsevier/Academic Press, 2009.

[4] R. Carriveau and InTech Open Access Books. Fundamental and Advanced Topics in Wind Power. Available:

http://www.intechopen.com/books/fundamental-andadvanced-topics-in-wind-power, 2011.

[5] T. Wildi, Electrical machines, drives, and power systems, 6th ed., International ed. ed. Upper Saddle River, N.J.: Pearson Education International, 2006.

[6] M. Hannachi and M. Benhamed, "Modeling and control of a variable speed wind turbine with a permanent magnet synchronous generator,"2017 International Conference on Green Energy Conversion Systems (GECS), Hammamet, pp. 1-6, 2017.

[7] M. Mirzaei and S. M. R. Mirjalili, "Direct drive field winding synchronous generators for medium power wind turbines,"6th IET International Conference on Power Electronics, Machines and Drives (PEMD 2012), Bristol, pp. 1-4, 2012.

[8] K. Patil and B. Mehta, "Modeling and simulation of variable speed wind turbine with direct drive permanent magnet synchronous generator,"2014 International Conference on Green Computing Communication and Electrical Engineering (ICGCCEE), Coimbatore, pp. 1-6, 2014.

[9] E. N. López-Ortiz, D. Campos-Gaona and E. L. Moreno-Goytia, "Modelling of a wind turbine with permanent magnet synchronous generator,"2012 North American Power Symposium (NAPS), Champaign, IL, pp. 1-6, 2012.

[10] V. Pickert, B. Zahawi, and D. Kalpaktsoglou, "Forced commutation controlled series capacitor (FCSC) circuit applied to stand-alone wave energy conversion buoys," Journal of Marine Engineering and Technology, vol. 10, pp. 15-23,2011.

[11] B. D. Deotaleand S. R. Paraskar, "Transient stability improvement using Thyristor Switched Series Capacitor (TSSC) FACTS device," in 2016 IEEE 
Students' Conference on Electrical, Electronics and [21] Computer Science (SCEECS), Bhopal, India, pp. 1-6., 2016.

[12] V. Pickert, D. Kalpaktsoglou, and A. Al-Busaidi, "Controlled series capacitor converters applied in generator-sets for SHEV's," in 24th International Battery, Hybrid and Fuel Cell Electric Vehicle Symposium and Exhibition 2009, EVS 24, Stavanger, pp. 1599-1603, 2009.

[13] B. S. Joshi, O. P. Mahela and S. R. Ola, "Implementation of Thyristor controlled series capacitor in transmission system to improve the performance of power system network,"2017 4th International Conference on Power, Control \& Embedded Systems (ICPCES), Allahabad, pp. 1-6, 2017.

[14] N. Johansson, L. Angquist and H. Nee, "An Adaptive Controller for Power System Stability Improvement and Power Flow Control by Means of a Thyristor Switched Series Capacitor (TSSC)," in IEEE Transactions on Power Systems, vol. 25, no. 1, pp. 381-391, Feb. 2010.

[15] B. S. Rigby, C. K. Ndlovu and R. G. Harley, "A thyristor-controlled series capacitor design for research laboratory application," 1999 IEEE Africon. 5th Africon Conference in Africa (Cat. No.99CH36342), Cape Town, South Africa,vol.2, pp. 903-908, 1999.

[16] M. Gheydi, P. Farhadi, S. Bagheri and A. Hematizadeh, "Impact of wind farm and thyristor-switched series capacitors in voltage, active and reactive power in normal condition of network," 10th International Symposium on Advanced Topics in Electrical Engineering (ATEE), pp. 693-698, 2017.

[17] W. Aslam, Y. Xu, A. Siddique and F. M. Albatsh, "Implementation of series facts devices SSSC and TCSC to improve power system stability," 13th IEEE Conference on Industrial Electronics and Applications (ICIEA), pp. 2291-2297, 2018.

[18] T. F. Chan and L. L. Lai, "Permanent-Magnet Machines for Distributed Power Generation: A Review," in 2007 IEEE Power Engineering Society General Meeting, pp. 1-6, 2007.

[19] P. J. Pyrhonen, and P. Kontkanen, "Axial Flux Permanent Magnet Generator with Concentrated Winding for Small Wind Power Applications," in IEEE International Conference on Electric Machines and Drives, pp. 1187-1191, 2005.

[20] D. A. F. Collier and M. L. Heldwein, "Modeling and design of a micro wind energy system with a variable speed wind turbine connected to a permanent magnet synchronous generator and a PWM rectifier, "in Power Electronics Conference (COBEP), Praiamar, Brazil, pp 292-299, 2011.
K. Subramanian, K. K. Ray, Synchronised Linear Ramp-Pulse Based Triggering Pulse Generation ON/OFF Control for Solid-State Switches: Capacitor Switching Applications, WSEAS Transactions on Power Systems, pp. 45-49, Issue 2, Volume 7, April 2012.

[22] R. Carbone, A passive power factor correction technique for single-phase thyristor-based controlled rectifiers, International Journal of Circuits, Systems and Signal Processing, pp.169-179, Issue 3, Volume 2, 2008.

[23] M. Nayeripour, M. M. Mansouri, Coordination of Overcurrent Protection and Fault Ride through Requirements of Doubly Fed Induction Generator in a Wind Turbine, International Journal of Mathematics and Computers in Simulation, pp.107-112, Volume 13, 2019.

\section{Contribution of individual authors to the creation of a scientific article (ghostwriting policy)}

Dimitrios Kalpaktsoglou carried out the simulation and the optimization.

Anastasios Tsiakalos carried out laboratory experiments.

Sotirios Pouros has organized and executed the experiments of Section 3.

Manos Roumeliotis was responsible for the editing of the paper.

\section{Creative Commons Attribution License 4.0 (Attribution 4.0 International, CC BY 4.0)}

This article is published under the terms of the Creative Commons Attribution License 4.0

https://creativecommons.org/licenses/by/4.0/deed.en_US 